\title{
Critérios Qualis A1 da Educação: a avaliação sob a perspectiva da disputa acadêmica
}

\author{
Daniele Alves Ribeiro \\ Universidade do Estado de Minas Gerais (UEMG) \\ Maria do Socorro Alencar Nunes Macedo \\ Universidade Federal de Pernambuco (UFPE) \\ Euclides de Freitas Couto \\ Universidade Federal de São João del Rei (UFSJ)
}

O objetivo deste artigo é refletir sobre os critérios do Qualis Periódico da Educação, mecanismo de avaliação dos periódicos, parte de um complexo sistema de avaliação dos programas de pós-graduação. Por meio do método documental, selecionamos como objeto de estudo os critérios A1 definidos pelo Documento de Área da Avaliação Trienal de 2013, os mais atuais da área da Educação. Com base nas discussões sociológicas da teoria de campo de Pierre Bourdieu, ao analisar cada um dos critérios, caracterizamos a revista como um agente sujeito às regras que regem a disputa pelo capital simbólico em jogo nesse microcosmo. Ainda que na esfera da prática, o processo avaliativo seja mais complexo do que prevê os documentos oficiais, a análise realizada evidencia como os critérios adotados pela Coordenação de Aperfeiçoamento de Pessoal de Nível Superior (Capes) traduzem as disputas acadêmicas em busca de legitimidade, por meio de disposições próprias adquiridas no interior do próprio campo.

Palavras-chave: Campo acadêmico brasileiro. Capital científico. Periódicos. Critérios Qualis A1 Educação. 


\section{Criteria Qualis A1 of Education: the evaluation through an academic contest}

Our objective in this article is to reflect about the criteria of Qualis Education Journal, an evaluation system of journals, which is part of a complex system to evaluate post graduation programs. Through the documental method, we selected the criteria A1 as defined by the 2013 Triennial Area Evaluation Document, the most modern in the Education field. Based in Pierre Bourdieu sociological discussion of the field theory, when we analyze each criterion, the magazine is typified as an agent subjected to the rules that conduct the struggle for the symbolical capital in this microcosm set. Even though, in the area of competence, the evaluation process is much more complex than the official documents predict, the criteria adopted by Capes show the academic competition to achieve the legitimacy by the inclinations acquired in the field as itself.

Keywords: Brazilian academic field. Scientific capital. Journals. Qualis A1 Education Criteria.

\section{Criterios Qualis A1 de la Educación: la evaluación so la perspectiva de la disputa académica}

El objetivo de este artículo es reflexionar sobre los criterios del Qualis, Periódico de la Educación, mecanismo de evaluación de los periódicos, parte de um complejo sistema de evaluación de los programas de posgraduación. A través del método documental, seleccionamos como objeto de estudio los criterios A1 definidos por el Documento del Área de Evaluación Trienal del año de 2013, los más actuales en el área de la Educación. Con base en las discusiones sociológicas de la teoría de campo de Pierre Bourdieu, al analizar cada uno de los criterios, caracterizamos la revista como un agente sujeto a las normas que dirigen la disputa por el capital simbólico en juego en este microcosmo. Aunque en la esfera de la práctica, el proceso de evaluación sea más complejo que los documentos oficiales, el análisis realizada pone en evidencia cómo los criterios adoptados por la Capes traducen las disputas académicas en la busca por la legitimidad a través de disposiciones propias adquiridas en el interior del mismo campo.

Palabras clave: Campo académico brasileño. Capital de la ciencia. Periódicos. Criterios Qualis A1 Educación. 


\section{Introdução}

No atual contexto de valorização da produção acadêmica, as discussões sobre os meios de divulgação da pesquisa e o aumento do número de periódicos científicos no Brasil têm ganhado espaço entre os pesquisadores de todas as áreas. Marcada pelas noções de dinamicidade, inovação científica e reconhecimento dos pares, surgiu a classificação Qualis Periódicos, que avalia as revistas que publicam textos de pesquisadores envolvidos com programas de pós-graduação em A1, A2, B1, B2, em uma escala que vai até B5 em diversas áreas do conhecimento. ${ }^{1}$

Para se qualificarem, os periódicos buscam captar textos de qualidade, entre outros requisitos técnicos. Por seu turno, para publicarem, os profissionais buscam periódicos de melhor avaliação, o que nem sempre é possível devido às grandes exigências dos editores e conselhos editoriais diante da ampla demanda para periódicos com qualificações mais altas. Assim, percebemos a constituição de dois agentes que se sobressaem no processo editorial de um periódico: os editores, para se qualificarem, por meio de políticas editoriais rigorosas, buscam adequar-se às exigências da Coordenação de Aperfeiçoamento de Pessoal de Nível Superior (Capes) e procuram desenvolver estratégias que levem os periódicos a serem bem classificados. Do outro lado, para publicarem, os profissionais buscam periódicos de melhor avaliação. Essa situação revela um ciclo cujos precedentes são marcados por um sistema e uma política de avaliação complexa que se inicia nos programas de pósgraduação brasileiros.

Este artigo é parte da pesquisa intitulada "Estratificação A1 na Educação: estratégias e legitimidade da educação em revista", a qual dedicou-se a entender quais são as estratégias de uma revista A1 para chegar ao topo da pirâmide e manter essa classificação. Para tanto, buscamos compreender os critérios Qualis Periódicos A1 da Educação sob a perspectiva da Teoria do Campo de Bourdieu, em uma tentativa de contribuir para as discussões sobre o entendimento do processo avaliativo dos periódicos da área da Educação.

Com vistas ao cotejamento do objeto de pesquisa, ou seja, os critérios Qualis A1, nossa análise baseou-se nos Documentos da Área da Educação (BRASIL, 2004; 2013), além de informações disponíveis no site da Capes que nos permitiram levantar as funções e caraterísticas do Qualis Periódicos. Para tanto, este texto é apresentado em três seções: na primeira, à luz dos conceitos formulados pelo sociólogo Pierre Bourdieu, são debatidos os conceitos de campo acadêmico, capital científico e agentes envolvidos na produção acadêmica; na segunda, traçamos um rápido

1 Pelo sistema Qualis da Capes, os periódicos são classificados quanto ao âmbito de circulação - internacional, nacional ou local - e quanto à qualidade de conteúdo e técnica. Os critérios para a classificação são atualizados por comissões específicas de cada área do conhecimento e podem ser observados no WebQualis, disponível em: <http://qualis.capes.gov.br/webqualis/ConsultaCriterio2004.faces>. 
panorama sobre a função do Qualis e os atuais critérios empregados pelos periódicos A1 da área da Educação; em seguida, analisamos estes critérios em diálogo com as teorias bourdieusianas, buscando evidenciar características do jogo científico.

\section{O campo, o capital e o agente}

O avanço do conhecimento e o desenvolvimento de ações institucionais e políticas que estimulam a pesquisa compõem uma realidade empírica para as discussões que ora propomos. Ao abordarmos o mundo das pesquisas científicas, suas publicações periódicas e, consequentemente, da avaliação da pós-graduação, tratamos de um grupo específico que atua em um determinado contexto em busca de um produto, a "verdade científica", a qual "reside numa espécie particular de condições de produção" (BOURDIEU, 2004b, p. 122).

Nas relações sociais que envolvem a produção científica, Bourdieu (2004b) destaca duas noções de ciência: uma engendrada em si mesmo, fora de intervenções do mundo, e outra diretamente ligada ao contexto social (relação texto-contexto). E é a partir destas duas noções de ciência que o teórico descreve as relações no interior do meio acadêmico ou científico. Ele destaca que uma ciência da ciência precisa recusar a oposição entre uma análise imanente ou interna (caberia à epistemologia) e uma externa (que relaciona os problemas de pesquisa às condições sociais de aparecimento). É também a partir destas duas noções que iremos abordar nosso objeto de pesquisa, os critérios Qualis A1, tendo em vista que a revista científica faz parte de um microcosmo que, por sua vez, está inserido em um macrocosmo, dentro de um contexto político-social. Sobre essa relação, Lahire (2002, p. 61) escreve: "um campo é um microcosmo incluído no macrocosmo constituído pelo espaço social (nacional) global".

Bourdieu explica que a origem do emprego do conceito de campo está ligada a essas duas noções de relações da ciência, a interna e a externa. Escreve ele se referindo à ideia de campo:

a noção serviu primeiro para indicar uma direção à pesquisa, definida negativamente como recusa à alternativa da interpretação interna e da explicação externa perante a qual se achavam colocadas todas as ciências das obras culturais, ciências religiosas, história da arte ou história literária: nessas ciências, a oposição entre um formalismo nascido da teorização de uma arte que chegara a um alto grau de autonomia e um reducionismo empenhado em relacionar diretamente as formas artísticas com formas sociais [...] encobria o que as duas correntes tinham em comum, a saber, o fato de ignorarem o campo de produção como espaço social de relações objetivas (BOURDIEU, 2000, p. 64). 
Nesse trecho, é possível perceber que a noção de campo e os conceitos que a cercam fazem parte de suas reflexões como opção para a diferença entre estruturalistas e construtivistas, entre o objetivismo e o subjetivismo.

Dessa forma, partimos do princípio de que para entender sobre a produção cultural, no nosso caso a produção científica, "não basta referir-se ao conteúdo textual dessa produção, tampouco referir-se ao contexto social, contentando-se em estabelecer uma relação direta entre texto e contexto" (BOURDIEU, 2004c, p. 20). Segundo Bourdieu, é necessário estudar o intermediário entre eles: o campo, que é o

universo em que está inserido os agentes e as instituições que produzem, reproduzem ou difundem a arte, a literatura ou a ciência. Um mundo social com "leis sociais" mais ou menos específicas. Espaço relativamente autônomo, um microcosmo com leis próprias (BOURDIEU, 2004c, p. 20).

O conceito de campo, então, vai além da noção de contexto, meio ou pano de fundo; é um universo próprio, com "regras" próprias, mas que se relaciona com outros campos sociais. Bourdieu considera que os campos são autônomos, mas que possuem "traços estruturalmente semelhantes", mas não idênticos. E, ao relacionar diferenças e semelhanças entre os campos, exemplifica o campo literário e o político e chama atenção:

relação complexa que vai se apresentar em destruir os que têm o hábito de pensar em termos de tudo ou nada. De um certo ponto de vista, o campo literário (ou científico) é um campo como os outros (contra todas as formas de hagiografia ou, simplesmente, contra a tendência de pensar que os universos sociais onde são produzidas essas realidade de exceção que são a arte, a literatura ou a ciência só podem ser totalmente diferentes, diferentes sob todos os aspectos): tratase de uma questão de poder - o poder de publicar ou de recusar a publicação, por exemplo -, de capital - o do autor consagrado que pode ser parcialmente transferido para a conta de um jovem escritor ainda desconhecido, por meio de um comentário elogioso ou de um prefácio -; aqui, como em outros lugares, observamse relações de força, estratégia, interesses etc. (BOURDIEU, 2004c, 170).

Ao utilizar o termo "capital", Bourdieu refere-se ao capital simbólico, que é o

reconhecimento ou consagração, institucionalizada ou não, que os diferentes agentes e instituições conseguiram acumular no decorrer das lutas anteriores, ao preço de um trabalho e de estratégias específicas. Ainda seria preciso determinar a natureza desse reconhecimento, que não se mede nem pelo sucesso comercial - na verdade, seria o oposto deste -, nem pela simples consagração social - pertencer às academias, obter prêmios etc. -, nem mesmo pela simples notoriedade, que, mal adquirida, pode levar ao descrédito (BOURDIEU, 2004c, p. 170-171).

É importante, então, refletirmos sobre o funcionamento do campo científico, ou seja, o campo científico em que a revista está inserida, buscando identificar quais são os 
bens escassos em disputa e os agentes que se entrecruzam nas lutas simbólicas.

O conceito de campo acadêmico ou científico, ${ }^{2}$ que abriga uma complexa rede de lutas pelo poder, jogo de interesses e estratégias, constitui-se como qualquer campo social, "mas onde todas essas invariantes revestem-se de formas específicas" (BOURDIEU, 1983, p. 122).

O campo científico, enquanto sistema de relações objetivas entre posições adquiridas (em lutas anteriores), é o lugar, o espaço de jogo de uma luta concorrencial. O que está em jogo especificamente nessa luta é o monopólio da autoridade científica definida de maneira inseparável, como capacidade técnica e poder social; ou se quisermos, o monopólio da competência científica, compreendida enquanto capacidade de falar e agir legitimamente (isto é, de maneira autorizada e com autoridade), que é socialmente outorgada a um agente determinado (BOURDIEU, 1983, p. 122-123, grifos do autor).

Nessa definição, Bourdieu destaca duas expressões: "autoridade científica" e "competência científica". Aqui, o autor deixa claro que as disputas e lutas do campo visam alcançar a legitimidade, ser autorizado e ter autoridade para representar a verdade científica, o que envolveria a capacidade técnica, além do poder social de determinado agente que atua nesse campo. Tendo em vista o processo de avaliação dos periódicos, é possível percebermos a presença desses conceitos na exigência da arbitragem por pares. A avaliação por pares é fator preponderante para a legitimidade da revista, do conhecimento produzido e da própria revista.

$\mathrm{Na}$ caracterização do campo científico, Bourdieu (1983) faz considerações importantes sobre as capacidades técnicas e as relações sociais que interferem no jogo pelo poder. Segundo ele, a autoridade ou a competência científica não depende somente da capacidade técnica para pesquisar e produzir, mas também dos títulos escolares - no caso das revistas, poderíamos relacionar o título às classificações feitas pela Capes - e às distinções científicas. Essa "ostentação" (BOURDIEU, 1983, p. 124), que parece tão autêntica entre os pesquisadores, está também relacionada ao social, atribuindo mais ou menos valor simbólico. "A carreira de um pesquisador não só é determinada pela sua capacidade técnica, mas está 'contaminada' pela posição que ele ocupa nas hierarquias instituídas" (BOURDIEU, 1983, p. 124).

Dentro de cada campo, segundo as teorias bourdieusianas, existe sempre um tipo de capital específico. No campo científico é o capital científico, uma espécie de capital simbólico, já que não tem um valor concreto, real, referindo-se ao conhecimento e ao reconhecimento do agente, principalmente entre os participantes do jogo, que na linguagem do campo científico são os chamados pares. Em Bourdieu (2004a), um

2 Conforme Bourdieu, não diferenciamos campo acadêmico de campo científico. Trabalhamos com a noção de campo como lugar de luta que rompe com a hagiografia e a própria sociologia, visto que não é o "reino dos fins' com concorrência pura das ideias. Seu funcionamento produz e supõe uma forma específica de interesses" (BOURDIEU, 1983, p. 123). 
dos exemplos desse reconhecimento e que cabe muito bem em nossa reflexão é o fator do impacto das revistas científicas. Quanto maior o fator de impacto, ou seja, o número de citações desta revista em artigos científicos, maior o reconhecimento dela.

Segundo o autor, o capital científico não é de natureza financeira; é o reconhecimento de uma competência, e este reconhecimento proporciona autoridade e contribui para definir regras e regularidades (as leis do que publicar, em qual periódico publicar). Portanto, a competência de determinada revista lhe proporciona cada vez mais autoridade e ela passa a funcionar como exemplo, padrão a ser seguido, e cada vez que ela atinge determinado ponto de qualidade, novas exigências surgem, ou seja, as regras do jogo vão sofrendo alterações, o que caracteriza, de forma explícita, a dinamicidade dos critérios de avaliação. Cabe ressaltar que as exigências para classificação das revistas são determinadas pela Capes, e os critérios para isso são discutidos pelas coordenações em reuniões com os membros de cada área, que são os próprios pesquisadores. Neste caso, observamos como a avaliação Capes, legitimada pela participação dos próprios agentes, proporciona ainda mais autoridade para revistas em estrados mais elevados. Assim, a revista, representada pelo(s) editor(es), luta pela melhor classificação, ao mesmo tempo em que autores, editores e avaliadores (também chamados revisores) lutam pela autoridade capaz de participar das decisões quanto às regras deste jogo. "O que está em jogo na luta faz parte da luta" (BOURDIEU, 1983, p. 129). Quem está já tem reconhecimento, "está no poder" e também precisa lutar para se manter e não só impor. "À medida que a própria definição dos critérios de julgamento e dos princípios de hierarquização estão em jogo na luta, ninguém é bom juiz porque não há juiz que não seja, ao mesmo tempo, juiz e parte interessada" (op. cit.). Quem avalia também é parte interessada em manter as exigências para que tudo continue em seus lugares. Quem dita as regras das revistas são os próprios profissionais de suas áreas, que estão na condição de dominantes, mas também precisam produzir de acordo com as exigências do sistema.

Dentro do jogo, se por um lado há os agentes que possuem autoridade e ditam as regras (dominantes), há também aqueles que tentam resistir (dominados). Assim, é possível ter noção de que ele é mesmo um campo de lutas, em que estão presentes dominantes e pretendentes (os novatos, como classifica Bourdieu). Nas palavras do autor:

como um bom jogador de rugby sabe para onde vai a bola e se põe lá onde a bola vai cair, o bom cientista jogador é aquele que, sem ter necessidade de calcular, de ser cínico, faz as escolhas que compensam. Aqueles que nasceram no jogo têm o privilégio do inatismo. Eles não têm necessidade de serem cínicos para fazer o que é preciso quando é preciso e ganhar a aposta (BOURDIEU, 1983, p. 28). 
Do outro lado:

aqueles que adquirem, longe do campo em que se inserem, as disposições que não são aquelas que esse campo exige, arriscam-se, por exemplo, a estar sempre defasados, deslocados, mal colocados, mal em sua própria pele, na contramão e na hora errada, com todas as consequências que se pode imaginar. Mas eles podem também lutar com as forças do campo, resistir-lhe e em vez de submeter suas disposições às estruturas, tentar modificar as estruturas em razão de suas disposições (BOURDIEU, 1983, p. 28-29).

As relações dentro do campo são complexas, já que não existe somente o capital científico puro, que é a capacidade técnica. É preciso pensar que nem todos os que estão envolvidos nesse jogo possuem a capacidade técnica a que se referia Bourdieu no primeiro momento. E como para estar no campo é preciso capital científico, ele diferencia o capital científico puro, ou a competência, e o capital científico institucional, o lugar social que o agente ocupa dentro do campo. Nas palavras do autor, são duas formas de poder que correspondem a duas espécies de capital científico e se misturam sem ser possível aferir valor a cada uma delas.

O capital científico institucionalizado é também chamado por Bourdieu de capital temporal ou político; é o poder institucional e institucionalizado - como, por exemplo, pertencer a comissões ou comitês avaliativos e chefiar departamentos - e o poder sobre os meios de produção e reprodução - por exemplo, os contratos, os créditos, o poder de nomear etc. (BOURDIEU, 2004a, p. 35).

Entretanto, o capital científico puro é o prestígio pessoal como reconhecimento do conjunto de pares ou da fração mais consagrada entre eles. Este capital é mais contestado e criticado do que o capital científico institucionalizado, que é instituído (BOURDIEU, 2004a, p. 36).

Para Bourdieu (2004a), esses dois tipos de capital têm também leis de acumulação diferentes. O puro é adquirido pelas contribuições reconhecidas às ciências, invenções ou descobertas, publicação em revista de prestígio, por exemplo. Já o institucional é adquirido, com o tempo, por estratégias políticas - participação em eventos, bancas, comissões.

O acúmulo desses capitais caracteriza o pesquisador, e a estrutura de seu capital dáse pelo peso relativo do capital puro e do institucional. Portanto, o autor destaca que entre os agentes existem dois extremos: os detentores de forte crédito específico, científico, junto aos pares e frágil peso político, e os detentores de forte peso político e frágil crédito científico, entre os quais ele destaca os administradores científicos (BOURDIEU, 2004a, p. 38).

Em função desse duplo caráter de capital, poderes temporais (capital científico institucional) e poderes específicos (capital científico puro), "os conflitos intelectuais são, também, sempre, de algum aspecto, conflitos de poder. Toda estratégia de 
um erudito comporta, ao mesmo tempo, uma dimensão política (específica) e uma dimensão científica [...]" (BOURDIEU, 2004a, p. 41). É possível, então, compreender a luta de uma revista pela melhor classificação dentro deste conflito de poder. Afinal, a Capes não avalia os textos da revista, seu conteúdo e a qualidade dos textos e pesquisas; ela se utiliza de critérios que verificam que tipo de cuidado a revista tem com o que é publicado, entre eles a variedade de filiações institucionais e a qualificação dos membros da comissão de avaliação, a variabilidade institucional de autores, entre outros que iremos discutir mais adiante e estão atrelados ao poder social dos envolvidos na arbitragem.

Como estão sujeitas a todas as regras do jogo, podemos dizer que as revistas, assim como os pesquisadores, são agentes desse complexo campo científico, sujeitas a estratégias para a acumulação de capital científico, seja puro e/ou institucional. Além do seu próprio capital, a revista beneficia-se ou não nesse jogo pelo capital dos pesquisadores e instituições atreladas a ela, seja como membros do conselho editorial, autores e, sobretudo, comissão de avaliação, que lhe garante a avaliação por pares. Isso porque os títulos escolares e as distinções científicas, o que Bourdieu chama de "competência" ou "autoridade científica", autênticos entre os pesquisadores, estão também relacionados ao social (capital social), ganhando novo sentido que lhe atribui ou não mais valor simbólico. "Assim, os julgamentos sobre a capacidade científica de um estudante ou de um pesquisador estão sempre contaminados, no transcurso de sua carreira, pelo conhecimento da posição que ele ocupa nas hierarquias instituídas" (BOURDIEU, 1983, p. 124, grifo do autor).

Vejamos, então, como os critérios Qualis referendam a posição da revista como agente do campo acadêmico.

\section{Qualis, indicador de capital simbólico}

A avaliação da produção docente e discente faz parte da avaliação dos programas de pós-graduação, sendo um item desta avaliação que envolve outros critérios. $\mathrm{Na}$ tentativa de tornar a avaliação da produção mais objetiva, a proposta da Capes foi estabelecer critérios que se tornaram base para estratificar os periódicos em que os pesquisadores estão publicando. Daí nasceu o sistema "Qualis Periódicos" que, dividido por áreas e por meio de suas comissões, avaliam os periódicos desde 1998, a fim de classificá-los, tornando possível a pontuação de determinada produção com base no periódico em que é publicada.

Portanto, Qualis é um aplicativo externo ao Sistema de Avaliação dos Programas de Pós-Graduação (DataCapes) e realiza um tratamento mais sistemático e qualitativo da produção científica dos programas, a fim de aperfeiçoar os indicadores que 
subsidiam a avaliação (SOUZA; PAULA, 2002, p. 10).

Após avaliar os periódicos citados no Coleta $^{3}$ como resultado da avaliação Qualis, a Capes

disponibiliza uma lista com a classificação dos veículos utilizados pelos programas de pós-graduação para a divulgação da sua produção. A estratificação da qualidade dessa produção é realizada de forma indireta. Dessa forma, o Qualis afere a qualidade dos artigos e de outros tipos de produção, a partir da análise da qualidade dos veículos de divulgação, ou seja, periódicos científicos e anais de eventos $^{4}$ (BRASIL, 2009).

Para destacar a função do Qualis, o que justifica toda a sua logística, Souza e Paula (2002), no artigo "Qualis: a base de qualificação dos periódicos científicos utilizada na avaliação Capes", publicado no InfoCapes, destacam a importância das publicações na avaliação dos programas. Segundo elas, a pesquisa e a produção científica são os indicadores de maior relevância na avaliação.

Sabe-se que dentro do conjunto de aspectos que caracterizam o desempenho dos mestrados e doutorados, os especialistas consideram a pesquisa e a produção científica de docentes e alunos como os indicadores mais relevantes na determinação do padrão de qualidade dos cursos. Daí a ênfase na importância da base Qualis no contexto da avaliação (SOUZA; PAULA, 2002, p. 6).

Para Jacon (2006), o lugar ocupado pelo periódico na produção do conhecimento no Brasil justifica a importância deste periódico na política de avaliação. "A quantidade das pesquisas publicadas em periódicos científicos contribui de forma significativa no cômputo total dos pontos alcançados e na nota atribuída na avaliação desses programas" (op. cit., p. 4).

A autora destaca, ainda, o funcionamento do Qualis e sua avaliação por pares (representada pelas comissões avaliativas). Segundo ela, apesar das diferenças entre as áreas, as comissões seguem os parâmetros gerais para aferição de qualidade dos periódicos concebidos pela base Qualis, "que se alicerça no processo de avaliação em ciência" (JACON, 2006, p. 5). Esse processo a que se refere é a avaliação por pares, o que legitima esta avaliação. Desta forma, "[...] um artigo publicado em uma revista não representa apenas a opinião do autor, leva também o selo da autoridade científica através do imprimatur dado pelo editor e os examinadores que ele possa ter

3 Coleta Capes é um sistema informatizado que auxilia na avaliação da Capes, coletando informações sobre os cursos de pós-graduação stricto e lato sensu.

4 "O Conselho Técnico-Científico da Educação Superior (CTC-ES) durante a 111 ${ }^{a}$ Reunião, realizada em 24 de agosto de 2009, aprovou o Roteiro para Classificação de Livros. O roteiro traz conceitos e definições comuns e sugestão de modelo de ficha de classificação e servirá como orientação para as 23 áreas que vão classificar livros na avaliação trienal de 2010". Mais informações disponíveis em: <http://www.capes.gov.br/avaliacao/ instrumentos-de-apoio/classificacao-da-producao-intelectual>. 
consultado" (ZIMAN, 1979, p. 124).

Observamos em Ziman (1979) e Jacon (2006) que, apesar da possibilidade de variação de indicadores de qualidade das revistas entre as áreas, a confiabilidade é garantida pelo processo científico de avaliação por pares, que legitima esta avaliação, a qual serve de base para financiamentos e bolsas da Capes, do Conselho Nacional de Desenvolvimento Científico e Tecnológico (CNPq) e de outras agências de fomento. Quanto à legitimidade, Souza e Paula (2002) ainda vão mais adiante:

outros fatores que legitimam esse sistema derivam do fato de a Capes buscar a participação da comunidade acadêmica no processo de tomada de decisão, a revisão periódica dos critérios e indicadores adotados, além de manter regularidade na avaliação, permitindo comparações em séries históricas. Com o tempo, os resultados dessa avaliação tornaram-se uma referência importante para as agências como o Conselho Nacional de Pesquisa (CNPq) e a Financiadora de Projetos (Finep), para nortear políticas e como suporte às decisões relacionadas às estratégias de apoio, financiamento e credenciamento da pós-graduação no país (SOUZA; PAULA, 2002, p. 9).

O processo de montagem da base Qualis aconteceu separadamente em cada uma das áreas de pesquisa da Capes, mas grande parte dele se deu entre os anos de 1998 e 2000 (SOUZA; PAULA, 2002). No ano 2000, todas as áreas já tinham seus critérios para avaliação dos periódicos definidos. Algumas concluíram a avaliação de 1998, quando utilizaram seus critérios, que já haviam sido divulgados. Outras já haviam definido, mas não utilizado e divulgado ainda.

Em relação aos critérios criados pelas áreas, apesar de diferenciados, Souza e Paula (2002) destacam que eles buscam fortalecer a legitimidade da avaliação, estando esta avaliação dos pares presente em todo o processo editorial e avaliativo do periódico. Os critérios e parâmetros utilizados pelas comissões vão permitir que os pares reconheçam a importância de determinada publicação, "gerando-se indicadores de reconhecida importância para a medição da ciência e avaliação da atividade científica" (op. cit., p. 9).

As discussões entre os agentes para a definição de critérios mais objetivos é, para Souza e Paula (2002), mais uma busca da legitimidade do processo, pois isto é capaz de garantir também avaliações mais "precisas", o que interfere nos investimentos de agências de fomento. As autoras afirmam:

a padronização é de importância vital para o aperfeiçoamento do indicador de produção científica por meio da classificação dos periódicos. Sem ela, será impossível uma classificação confiável, em função do grande número de repetições e do volume da base, como resultado de diversas formas de registrar um mesmo veículo, dificultando o trabalho das comissões de área (SOUZA; PAULA, 2002, p. 12). 
Em outro trecho, completam:

apesar de a avaliação baseada no conhecimento dos especialistas da área ser uma modalidade de avaliação aceita pelos pares que fazem parte das comissões de avaliação da Capes, quanto mais objetivos, claramente definidos e divulgados os critérios para a classificação dos veículos de publicação mais fundamentada e legitimada ela será. Isso, além de evitar a análise exclusivamente subjetiva pelos membros das comissões, também evita muitas mudanças a cada avaliação de programas, o que asseguraria maior legitimidade à base Qualis como instrumento da avaliação. Além disso, o estabelecimento de critérios de classificação claros, objetivos e de fácil aplicação permite aos próprios programas acompanharem a classificação de sua produção científica (SOUZA; PAULA, 2002, p. 20).

Apesar da busca pela objetividade, por meio da padronização de critérios, conforme exposto por Souza e Paula (2002), não há como escapar de certa subjetividade dos membros da comissão avaliadora.

Diante dessas colocações, antes de partirmos para os critérios específicos da Educação, chamamos a atenção para a dinamicidade da Qualis e dos critérios de avaliação dos periódicos, a exemplo do que aconteceu também com a avaliação dos programas de pós-graduação.

A base Qualis tem se mostrado dinâmica desde a sua implantação, havendo um constante movimento das Comissões de Área empenhadas na construção de mais esse indicador da produtividade científica. Atualmente, as comissões mais familiarizadas com o processo criam mecanismos de avaliação, seja reunindo as coordenações de pós-graduação para deliberação de critérios de avaliação, seja elaborando esses critérios.

[...] a dinamicidade da Qualis caracteriza-se também pela possibilidade de, a cada avaliação dos programas de avaliação, serem inseridos novos títulos, retirados outros ou ainda trocados em razão da mudança de nome em algum periódico constante na base. Essas características dotam a base Qualis de uma dinâmica própria, tendendo a ser um processo em contínuo aperfeiçoamento (SOUZA; PAULA, 2002, p. 13).

Podemos aqui trazer à tona as discussões de Neves (2002), para destacarmos a dinamicidade desse processo avaliativo. Ao discutir o processo de avaliação da pós-graduação, o autor destaca as mudanças a que estão sujeitos os padrões de qualidade, os quais estendemos para os critérios de qualidade do periódico:

a avalição tornou-se uma avaliação competitiva entre os programas, a partir de indicadores de excelência de qualidade que a cada momento poderiam ser movidos para cima [...]. Alcançando certo patamar de desenvolvimento, eleva-se o nível de qualidade exigido (NEVES, 2002, p. 6). 
Portanto, o processo é dinâmico, assim como são dinâmicos a construção do conhecimento, o número de publicações, os membros dos comitês e os critérios de avaliação dos periódicos.

Na área da Educação, a avaliação da pós-graduação no biênio 1998-2000 já registrou alterações, como aconteceu nas avaliações em geral. Verificando o Documento de Área referente ao processo (BRASIL, 2002), observamos que a avaliação dos 55 programas de pós-graduação para o biênio 1998-2000 foi feita com base em sete quesitos (segundo proposta da Capes): proposta do programa, corpo docente, atividade de pesquisa, atividade de formação, corpo discente, teses e dissertações, produção intelectual, cada um com seus devidos itens e indicadores. Segundo o documento, alguns itens são propostas da Capes, outros foram acrescentados pela Comissão da Área de Educação. Os instrumentos utilizados foram as fichas de avaliação dos programas, preparadas pela Capes, e as fichas de indicadores de cada item, preparadas pela área (op. cit., p. 1).

Em relação à avaliação 2001-2007, ao fazerem um relato sobre o Qualis periódico, Sousa e Macedo (2009) destacam que a ênfase evidenciada nos produtos, especialmente bibliográficos - que havia começado a ser construída na avaliação 1996-1997 - foi se intensificando, assim como ganhou intensidade também o processo de formação do aluno, para o qual começaram a surgir critérios capazes de controlar o nível de formação discente "a partir das produções dos alunos, dos egressos e da coerência das dissertações e teses com as linhas de pesquisa e com a proposta dos programas" (op. cit., p. 257).

A primeira avaliação da área de Educação que contou com os critérios Qualis foi a primeira trienal, realizada em 2004, referente aos anos 2001, 2002 e 2003. Ao final dela, a área da Educação publicou um documento completo, detalhando e ressaltando inclusive a criação dos critérios Qualis no primeiro semestre de 2004.

Para a avaliação 2001-2003, a Capes definiu que os periódicos seriam enquadrados em categorias que indicam qualidade (A, B e C) e o âmbito de circulação (local, nacional e internacional). Os indicativos de qualidade $A, B$ e $C$ eram aferidos pelos critérios normalização, publicação, circulação, autoria e conteúdo e gestão editorial, os quais, segundo Sousa e Macedo (2009), foram resultado de uma parceria com a Associação Nacional de Pesquisa e Pós-graduação (Anped), que havia realizado uma avaliação prévia considerando tais critérios. As autoras explicam que a avaliação da Anped foi feita com 60 revistas. Quando saiu a lista de publicações citadas no Coleta Capes, era necessária a avaliação de 607 revistas. Portanto, a comissão de área montou nova comissão para avaliar estas revistas citadas no Coleta.

Quanto à circulação, Sousa e Macedo (2009) destacam que os periódicos estrangeiros seriam internacionais e os brasileiros, nacional ou local. "Apenas alguns brasileiros foram classificados como internacional [...], tendo em vista sua circulação e também sua qualidade" (op. cit., p. 260). 
$\mathrm{Na}$ avaliação 2004-2006, uma nova comissão manteve os critérios da anterior. A parceria também solicitou à Anped a atualização/ampliação da avaliação anterior (SOUSA; MACEDO, 2009, p. 262) para a qual também foi construída nova comissão. Como não houve tempo suficiente para que a Anped concluísse o trabalho, utilizouse a avaliação de 2003, mas "para que não houvesse prejuízos dos periódicos que melhoraram ao longo do período, alguns não foram qualificados em estratos superiores" (op. cit.). Nessa avaliação foram avaliadas 1.308 revistas.

No triênio 2007-2009, foram realizados estudos, iniciados logo em 2007, para uma avaliação dos critérios, a partir dos quais a Capes propôs mudanças na ficha de avaliação e no Qualis. Segundo Sousa e Macedo (2009), os estudos mostraram diferenças quanto ao que as áreas entendiam como internacional, se com base no público-alvo, na circulação ou uma mistura entre lugar de publicação e nível, como era o caso da Educação. Associado a isso, a variação de estratos entre áreas permitia que um mesmo periódico se encontrasse em estratos locais e internacionais em áreas diferentes.

Assim, o Conselho Técnico Científico (CTC) da Capes definiu novos estratos: A1, A2, B1, B2, B3, B4, B5 e C, ${ }^{5}$ este último quando for considerado um periódico impróprio. A princípio, "esperava-se que os estratos superiores (A) não congregassem mais que $20 \%$ da produção da área (em número de textos) e que os demais periódicos estivessem regularmente distribuídos pelos estratos B" (SOUSA; MACEDO, 2009, p. 263). Portanto, posteriormente, o CTC ampliou para $26 \%$ (em número de periódicos) o limite de periódicos nos estratos A, o que começou a vigorar a partir de 2007.

Outra alteração destacada por Sousa e Macedo (2009, p. 263) é que "cada área passaria a submeter à apreciação do CTC não apenas os critérios para a definição dos estratos, mas a listagem de periódicos classificados".

Nesse contexto, a área de Educação estabeleceu novos indicadores que englobavam normalização, gestão editorial, conteúdo, autoria e indexação. Para a indexação, Sousa e Macedo (2009, p. 264) chamam atenção para o sentido mais "genérico" desse critério, "respeitando o fato de tal procedimento não ser ainda amplamente utilizado na área, tanto no Brasil quanto em nível internacional".

O fator de impacto foi um critério que na área de Educação continuou não sendo considerado. Segundo as autoras, essa decisão deve-se ao fato de que os estudos sobre "índice de impacto de periódicos demonstram que tais indicadores não informam sobre o impacto de cada artigo isolado" (SOUSA; MACEDO, 2009, p. 267).

\section{QUADRO 1}

$5 \mathrm{Na}$ atual lista de publicações/área/estratificação do WebQualis,da área de Educação, constam 2.341 periódicos, entre os quais: 144 classificados como A1; 169 como A2; 322 como B1; 377 como B2; 389 como B3; 455 como B4; e 485 como B5. Mais informações disponíveis em: <http://qualis.capes.gov.br/webqualis/publico/ pesquisaPublicaClassificacao.seam>. 


\begin{tabular}{l|l}
\hline Estrato & \multicolumn{1}{c}{ Definição } \\
\hline \multirow{4}{*}{ A1 } & $\begin{array}{l}\text { Publicação amplamente reconhecida pela área, seriada, arbitrada e dirigida } \\
\text { prioritariamente à comunidade acadêmico-científica, atendendo a normas } \\
\text { editoriais da ABNT ou equivalente (no exterior). Ter ampla circulação por } \\
\text { meio de assinaturas/permutas para a versão impressa, quando for o caso, } \\
\text { e on-line. Periodicidade mínima de } 3 \text { números anuais e regularidade, com } \\
\text { publicação de todos os números previstos no prazo. Possuir conselho } \\
\text { editorial e corpo de pareceristas formado por pesquisadores nacionais e } \\
\text { internacionais de diferentes instituiçōes e altamente qualificados. Publicar, } \\
\text { no mínimo, } 18 \text { artigos por ano, garantindo ampla diversidade institucional } \\
\text { dos autores: pelo menos 75\% de artigos devem estar vinculados a no } \\
\text { mínimo } 5 \text { instituiçōes diferentes daquela que edita o periódico. Garantir } \\
\text { presença significativa de artigos de pesquisadores filiados a instituições } \\
\text { estrangeiras reconhecidas (acima de dois artigos por ano). Estar indexado } \\
\text { em, pelo menos, } 6 \text { bases de dados, sendo, pelo menos, } 3 \text { internacionais. }\end{array}$ \\
\hline
\end{tabular}

Fonte: Brasil (2009) apud Sousa e Macedo (2009, p. 264).

Obs.: Além deste, o Documento de Área define os critérios A2 e B (B1 a B5). Porém, nosso interesse aqui é a classificação A1, por isso optamos por não reproduzir o quadro completo.

Destacamos, conforme relato dos Documentos da Área e de Sousa e Macedo (2009), a parceria com a Anped e o Comitê de Educação do CNPq, o que contribuiu para a legitimação do processo com a participação dos envolvidos. Como afirmam Sousa e Macedo, essas parecerias permitem "decisões em consonância com a área", pois elas "têm implicações sobre a política de pós-graduação e pesquisa" (op. cit., p. 268). A avaliação 2007-2009 representou o momento de criação de um modelo que seria consolidado na avaliação posterior, para o triênio 2010-2013.

\section{Os critérios A1 sob a perspectiva da disputa}

Com base nas disputas em jogo dentro do campo acadêmico e na posição de agente ocupada pelas revistas científicas, seria possível pensarmos alguns critérios de avaliação dentro da Teoria do Campo, considerando o capital puro ou institucional, o capital social, o poder puro e o institucionalizado, as posições de dominante e dominados. 
Para isso, utilizaremos os critérios para o estrato A1, em que se encaixa o nosso objeto de pesquisa: "publicação amplamente reconhecida pela área, seriada, arbitrada e dirigida prioritariamente à comunidade acadêmico-científica".

O "dirigida prioritariamente à área acadêmica" permite-nos pensar em termos de capital puro, intrínseco ao campo. "Ser amplamente reconhecida pela área" já nos permite pensar o envolvimento do capital social, pois, como nos diz Bourdieu, os valores atribuídos pelas hierarquias instituídas, ou seja, atribuir maior ou menor valor à pessoa, instituição ou publicação é um capital simbólico baseado não só no capital puro, mas também no social. Aqui vemos também a importância do capital científico, do valor do reconhecimento capaz de conferir legitimidade ao que a revista publica. "Arbitrada" é a exigência de que os textos publicados sejam aprovados pelos pares, agentes do campo tidos como dominantes.

Quanto aos critérios que definem a "periodicidade mínima de três números anuais e regularidade, com publicação de todos os números previstos no prazo" e "publicar, no mínimo, 18 artigos por ano, garantindo ampla diversidade institucional dos autores (pelo menos 75\% de artigos devem estar vinculados a, no mínimo, cinco instituições diferentes daquela que edita o periódico)", significa que três números anuais com, no mínimo, 18 artigos por ano, exigem que cada número da publicação dentro de determinado ano tenha, no mínimo, seis artigos, entre os quais quatro ou cinco de instituições diferentes da que edita o periódico. É possível observar que quanto mais alta a estratificação, maior a exigência quanto à quantidade de números anuais, de artigos e de variedade de instituições. Essa ordem nos desperta para a questão da dinamicidade da produção do conhecimento, quanto mais e mais rápido melhor. $\mathrm{Na}$ teoria do campo, Bourdieu (1983) trata essa questão como a "precipitação em publicar" para evitar ser ultrapassado, já que o capital de autoridade é monopolizado pelo primeiro que faz a descoberta. Se muitos estão envolvidos com tal descoberta, o primeiro é o que tem maior grau de autoridade, que vai caindo à medida que outros vão fazendo o mesmo estudo. Em nota de rodapé, Bourdieu (1983) cita rapidamente a questão de print e reprint, modalidades de comunicação científica atreladas à revista e que são publicadas antes mesmo da versão final da publicação, uma estratégia para ganhar tempo, saindo na frente, e espaço entre determinado público.

[...] A primeira consiste em divulgar os produtos rapidamente, escapando aos prazos das publicações científicas (vantagem importante nos setores altamente produtivos). A segunda consiste em divulgar mais amplamente junto ao conjunto dos colegas ou da demanda, produtos marcados e socialmente imputados a um nome próprio (BOURDIEU, 1983, p. 132).

"Possuir [...] corpo de pareceristas formados por pesquisadores nacionais e internacionais de diferentes instituições e altamente qualificados". Aqui é possível ver novamente a questão do capital. "Altamente qualificados" reafirma nossa colocação a respeito da legitimidade e do reconhecimento de quem aprova os 
textos para serem publicados. Nas revistas, é interessante observar esse papel dos pareceristas em aprovar, ou seja, em reconhecer o que é produzido pelo autor. Isso justificaria a exigência da Capes para que revistas $\mathrm{A} 1$ da área de Educação tenham pareceristas pesquisadores nacionais e internacionais de diferentes instituições e altamente qualificados.

No critério "garantir presença significativa de artigos de pesquisadores filiados a instituições estrangeiras reconhecidas (acima de dois artigos por ano)", é possível analisarmos a questão do regional, nacional e internacional. A discussão sobre a internacionalidade, o reconhecimento dos pares internacionais, nos remete à "objetividade ingênua" de Bourdieu (1983). Segundo o autor, o recurso de recorrer a "juízes" internacionais para legitimar uma pesquisa ou um pesquisador não foge aos interesses do campo.

[...] A ingenuidade técnica dos "juízes" a que recorre comumente a tradição científica para definir as hierarquias características de um campo determinado [...]. É a mesma filosofia ingênua da objetividade que inspira o recurso a "especialistas internacionais". Como se a posição de observadores estrangeiros pudesse colocálos ao abrigo dos parti pris e das tomadas de posição num momento em que a economia das trocas ideológicas conhece tantas sociedades multinacionais. E ainda como se suas análises científicas de estado da ciência pudessem ser outra coisa que não a justificação, cientificamente mascarada, do estado particular da ciência ou das instituições científicas com o qual compactuam (BOURDIEU, 1983, p. 130).

"Estar indexado em, pelo menos, seis bases de dados, sendo, pelo menos, três internacionais" é mais um critério que destaca a importância do reconhecimento e a questão da nacionalidade.

Podemos, então, considerar a revista como um agente do campo: um agente envolvido em um jogo de "relações objetivas entre posições adquiridas (em lutas anteriores)" (BOURDIEU, 1983, p. 123). Pois, ainda retomando Bourdieu (2004), lembramos que é o acúmulo de capitais (puro ou institucional) que caracteriza o pesquisador, existindo dois extremos: "os detentores de forte crédito específico, científico, junto aos pares e frágil peso político, e os detentores de forte peso político e frágil crédito científico" (BOURDIEU, 2004, p. 38).

Segundo o autor, esses seriam os extremos de uma linha imaginária em que estão todos os envolvidos no campo acadêmico: agentes e instituições. Pensemos, então, o nosso objeto de pesquisa: as revistas. Elas, como agentes, também estariam distribuídas nessa linha, cujos extremos são revistas detentoras de forte crédito específico (científico) junto aos pares e frágil peso político, e as detentoras de forte peso político e frágil crédito científico.

Porém, independentemente do lugar em que a revista encontra-se dentro desses extremos, poderíamos também dizer, ainda de acordo com as ideias bourdieusianas, 
que todas as escolhas do editor ou da comissão editorial, sejam conscientes ou inconscientes, são estratégias políticas de investimento objetivamente orientadas para aumentar o lucro científico, o reconhecimento dos pares (BOURDIEU, 1983).

\section{Conclusão}

Bourdieu, em suas discussões sobre a Teoria do Campo, nos desperta para algumas reflexões sobre as relações que se estabelecem no campo acadêmico, sejam elas exclusivamente internas ou também em relação ao macrocosmo em que se encontra esse campo. Ao caracterizar os agentes participantes desse jogo, o autor, a princípio, nos remete aos pesquisadores e às instituições. Porém, é possível observamos que dentro deste campo existem outros "microcampos", entre os quais o complexo sistema de avaliação da pós-graduação e, consequentemente, dos periódicos, em que esses meios de divulgação científica enquadram-se em uma disputa coerente ao campo em que estão inseridos. Portanto, uma das primeiras conclusões a que chegamos é a condição de agente do campo das revistas científicas. Inseridas no que o autor chama de "jogo do poder", elas buscam, por meio de disposições específicas, acumular capital científico, puro e institucional, para se legitimarem no contexto em que se inserem. É possível essa conclusão a partir dos critérios a que estão sujeitas. Sendo assim, cada revista, dentro da sua própria área, busca atender aos critérios, muitas vezes sem que os editores e envolvidos reflitam sobre os significados que eles possuem dentro da disputa.

Partindo dessa constatação, começamos a buscar entendimento sobre o lugar que a avalição dos periódicos ocupa no Sistema de Avaliação da Pós-Graduação. Então, observamos que a classificação desses divulgadores foi sofrendo alterações, mas sempre com o propósito de atribuir valores "objetivos" à produção docente e discente dos programas, mas, como vimos, o processo de avaliação e constituição do Qualis é cerceado de questões subjetivas marcadas pelas relações de poder no campo acadêmico.

Uma questão que se coloca é como fazer essa avaliação sem que as comissões da Capes, que são formadas também por pesquisadores-produtores, precisem ler cada artigo da revista, o que tornaria o trabalho inviável pela grande quantidade de revistas científicas em circulação disponíveis à publicação da produção acadêmica. A estratégia do Qualis aponta para que os critérios, baseados nas disputas existentes no campo acadêmico, tenham como foco observar quem realiza as avaliações cegas do material a ser publicado, seus capitais puros e institucionais, bem como as bases de indexação em que a revista está disponível, a sua abrangência, ou seja, o fato de ter boa circulação e alto fator de impacto ou grande número de citação, legitimando a revista segundo as regras de reconhecimento dos pares, existentes no campo 
científico e indicando, com isso, um maior ou menor capital científico.

Como agente do campo acadêmico, temos que considerar também que a revista está diretamente inserida nas disputas entre dominantes e dominados. Sendo assim, da mesma maneira que os pesquisadores, elas também estão inseridas em uma constante disputa por se manterem na classificação em que se encontram, trabalhando com disposições que não as permitam cair na estratificação, já que a lista do Qualis é dinâmica e está sujeita a alterações a cada três anos. Nessa dinamicidade podemos ver também que, à medida que um maior número de revistas aproxima-se da classificação A1, por exemplo, haveria a necessidade de alteração dos critérios. Nessa direção, vale a pena refletir, então, sobre a lógica do campo, na tentativa de entender que os critérios oficiais traduzem questões intrinsecamente ligadas ao campo acadêmico e a suas relações de poder.

\section{Referências}

BOURDIEU, P. O campo científico. In: ORTIZ, R. (Org.). Pierre Bourdieu: sociologia. São Paulo: Ática, 1983.

. A gênese dos conceitos de habitus e de campo. In: . (Org.). O poder simbólico. Tradução de Fernando Tomaz. Rio de Janeiro: Betrand Brasil, 2000. (Coleção Memória e Sociedade).

. Da regra às estratégias. In: . (Org.). Coisas ditas. Tradução de Cássia R. da Silveira e Denise Moreno Pegorina. São Paulo: Brasiliense, 2004a. p. 77-95.

. Os usos sociais das ciências: por uma sociologia clínica do campo científico. São Paulo: Editora Unesp, 2004b.

. O campo intelectual, um mundo à parte. In: (Org.). Coisas ditas. Tradução de Cássia R. da Silveira e Denise Moreno Pegorim. São Paulo: Brasiliense, 2004c. p. 169-179.

BRASIL. Ministério da Educação. Coordenação de Aperfeiçoamento de Pessoal de Nível Superior. Avaliação da pós-graduação: documento de área. Brasília: Capes, 2002. Disponível em: <http://www.capes.gov.br/images/stories/download/ avaliacao/2000_038_Doc_Area.pdf>. Acesso em: 30 jun. 2014.

- Avaliação da pós-graduação: documento de área. Brasília: Capes, 2004. Disponível em: <http://www.capes.gov.br/images/stories/ download/avaliacao/2003_038_Doc_Area.pdf>. Acesso em: 3 jul. 2014.

. Capes aprova a nova classificação Qualis. Brasília: Capes, 
2009. Disponível em: <http://www.capes.gov.br/component/content/article/36noticias/2550-capes-aprova-a-nova-classificacao-do-Qualis>. Acesso em: 18 jun. 2014.

Capes, 2013. Disponível em: <https://docs.google.com/

Relatório de Avaliação 2010-2012: trienal 2013. Brasília:

Recebido em julho de 2015.

Aprovado em outubro de 2015.

Daniele Alves Ribeiro é mestre em Educação pela Universidade Federal de São João del-Rei (UFSJ). Tem experiência na área de editoração e revisão de publicações científicas. Trabalha na Editora da Universidade do Estado de Minas Gerais (EdUEMG). E-mail: < daniribeiro3@hotmail.com>.

Maria do Socorro Alencar Nunes Macedo é doutora em Educação pela Universidade Federal de Minas Gerais (UFMG) e pós-doutora pelo Kings College, University of London (Londres). Professora da Universidade Federal de São João del-Rei (UFSJ), atualmente cedida para a Universidade Federal de Pernambuco (UFPE), Centro de Educação, atuando no Programa de Pós-Graduação em Educação da UFPE. É pesquisadora da área de letramento e alfabetização. Vice-presidente da Associação Brasileira de Alfabetização (Abalf). E-mail: <socorronunesmacedoufsj@gmail.com>.

Euclides de Freitas Couto é doutor em História pela Universidade Federal de Minas Gerais (UFMG) e professor do Programa de Pós-Graduação em História do Departamento de Ciências Sociais da Universidade Federal de São João del-Rei (UFSJ), onde desenvolve pesquisas nas áreas da História, Sociologia do Esporte e das Artes Visuais.E-mail: <euclides@ufsj.edu.br>. 